\title{
Pfeiffer type cardiocranial syndrome: a third case report
}

Lori Williamson-Kruse, Leslie G Biesecker

\begin{abstract}
Pfeiffer-type cardiocranial syndrome is a rare condition reported previously in three patients, two of whom were sibs. All three patients shared features that included growth and developmental retardation, sagittal synostosis, hypertelorism, low set ears, micrognathia with mandibular ankylosis, congenital heart defects, and genital anomalies. The purposes of this report are to present a fourth patient with features of the Pfeiffer-type cardiocranial syndrome, to expand the clinical phenotype of this condition, and to present evidence that supports the concept that this phenotype represents a distinct nosological entity.
\end{abstract}

( $\mathcal{F}$ Med Genet 1995;32:901-903)

Craniosynostosis may occur alone or as part of a multiple anomaly syndrome, of which more than 90 are currently known. ${ }^{12}$ The inheritance pattern, associated anomalies, and frequency of these disorders vary widely. Further delineation of rare craniosynostosis syndromes is important for accurate genetic counselling and prognosis determination, as well as to direct appropriate medical evaluation of affected patients. In addition, an understanding of isolated and syndromic craniosynostosis will provide clues to the genetics and pathogenesis of craniosynostosis.

The Pfeiffer type cardiocranial syndrome has been described previously in three patients. ${ }^{34}$ Features present in all patients included growth and developmental retardation, sagittal synostosis, micrognathia with mandibular ankylosis, congenital heart defects, microphallus, and cryptorchidism. Additional features that were observed in individual patients included tracheobronchial anomalies, large joint contractures, and cutaneous syndactyly. The inheritance pattern of this disorder is not known. We describe a male with a similar pattern of malformations and argue that this combination of anomalies represents a distinct syndrome.

\section{Case report}

The proband was the product of a 40 week dizygotic twin pregnancy to a 36 year old, gravida 12 , para 13 woman. His birth weight was $2600 \mathrm{~g}$ ( $\sim 3 \mathrm{rd}$ centile) and birth length was $46 \cdot 25 \mathrm{~cm}$ (<3rd centile). Supplemental oxygen was required at delivery, but no other resuscitative support was indicated. Dysmorphic features were noted at birth, but no major anomalies were apparent. He was discharged at 2 days of age. For the first four weeks of life he remained tachypnoeic and had radiographical evidence of atelectasis. The proband now has 15 sibs ranging in age from 8 months to 19 years. One sib died in infancy secondary to respiratory arrest. He was not dysmorphic or developmentally delayed. No other members of the immediate family, including the proband's twin sister, have dysmorphic features, delayed development, or synostosis. At the age of 3 months his weight was $6.9 \mathrm{~kg}$ ( $\sim 75$ th centile), height was $56 \mathrm{~cm}$ ( $\sim 10$ th centile), and head circumference was $43 \mathrm{~cm}$ ( $\sim 95$ th centile).

At the age of 9 months his weight was $6.8 \mathrm{~kg}$ ( $<5$ th centile), height was $68 \mathrm{~cm}(\sim 5$ th centile), and head circumference was $46 \mathrm{~cm}(\sim 50$ th centile). At $4 \frac{1}{2}$ years his weight was $12 \cdot 3 \mathrm{~kg}$ and his length was $91 \mathrm{~cm}$ (both $<5$ th centile). Clinical genetics examination at 9 months showed a ridged sagittal suture associated with a prominent frontal area and dolichocephaly (fig 1). There was torticollis and craniofacial asymmetry. His hair was sparse and fine with a central occipital whorl. His facial features included downward slanting palpebral fissures, an inner canthal distance of $2.7 \mathrm{~cm}(\sim 95$ th centile), an outer canthal distance of $7.4 \mathrm{~cm}$ ( $\sim 90$ th centile), wide nasal bridge, prominent and asymmetrical philtrum, highly arched palate, micrognathia, posteriorly rotated and low set left ear, and bifid uvula. There were prominent palmar creases, an underdeveloped hypothenar eminence, slender fingers, bilateral camptodactyly of the second digit, and partial cutaneous syndactyly of the second, third, and fourth toes bilaterally. Mild, diffuse flexion contractures of the feet were present. The patient had a small umbilical hernia, first degree hypospadias, and cryptorchidism. High resolution chromosome analysis ( 800 bands) was normal. Screening tests for amino and organic aciduria were normal. Skull radiographs were of poor quality and difficult to interpret. However, on the basis of the patient's sagittal ridging and dolichocephaly, we conclude that at least partial synostosis of the sagittal suture was present. Renal and head ultrasounds were normal with the exception of mild left ventricular enlargement. An echocardiogram performed at 4 years of age showed normal intracardiac anatomy. At the age of $4 \frac{1}{2}$ years the patient has severe to profound developmental delay. $\mathrm{He}$ does not sit, feed himself, babble, or have any receptive or expressive speech.

\section{Discussion}

The features in this patient are very similar to those described by Pfeiffer $e t a l^{3}$ and Stratton 


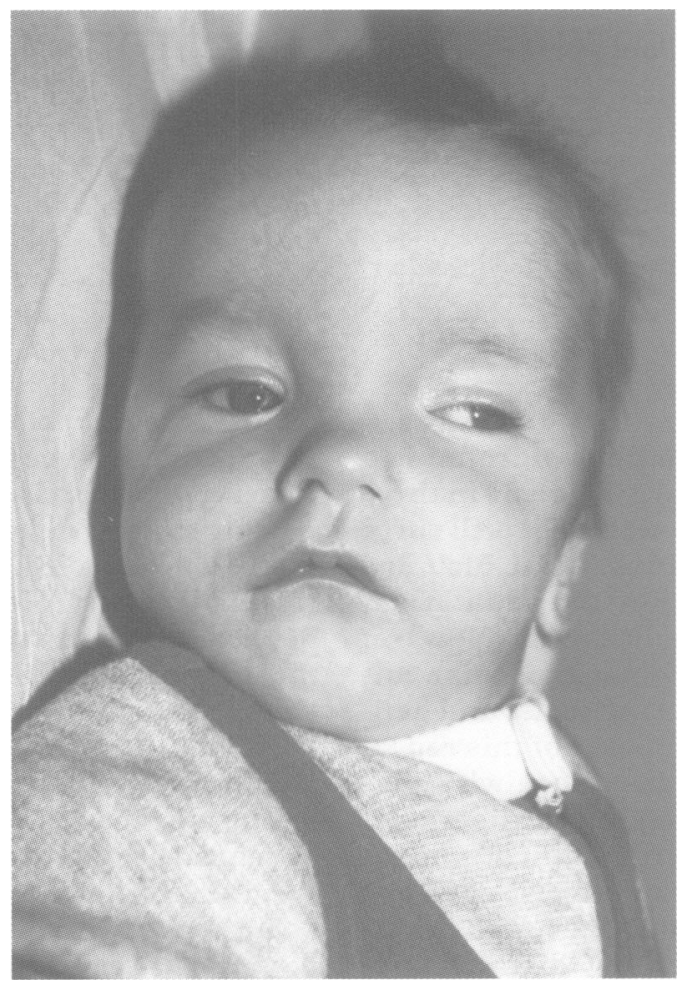

Figure 1 Front view of the patient shows plagiocephaly and asymmetry, disconjugate gaze, Cupid bow mouth, telecanthus with wide nasal bridge, and prominent forehead.

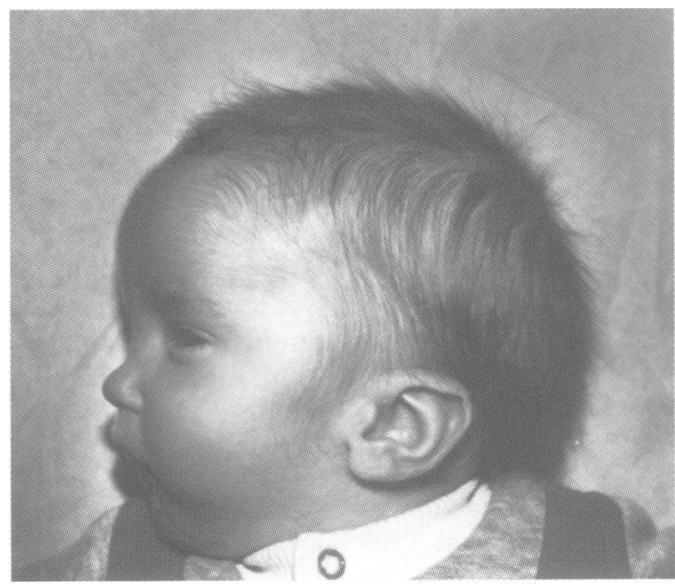

Figure 2 Lateral view of the patient shows an abnormal hair pattern, low set and posteriorly rotated ears, and micrognathia.

Major manifestations of Pfeiffer type cardiocranial syndrome

\begin{tabular}{|c|c|c|c|c|}
\hline Feature & $\begin{array}{l}\text { Pfeiffer et al } \\
\text { (patient 1) }\end{array}$ & $\begin{array}{l}\text { Pfeiffer et al } l^{3} \\
\text { (patient 2) }\end{array}$ & $\begin{array}{l}\text { Stratton and } \\
\text { Parsons }\end{array}$ & $\begin{array}{l}\text { Present } \\
\text { case }\end{array}$ \\
\hline Gender & $M$ & $\mathrm{~F}$ & $M$ & $\mathbf{M}$ \\
\hline Growth retardation & + & + & + & + \\
\hline $\begin{array}{l}\text { Mental retardation or } \\
\text { developmental delay }\end{array}$ & + & + & + & + \\
\hline Sagittal synostosis & + & + & + & + \\
\hline Low set ears & + & + & + & + \\
\hline Hypertelorism & + & + & + & + \\
\hline Mandibular ankylosis & + & + & + & - \\
\hline Micrognathia & + & + & + & + \\
\hline Heart defect & + & + & + & - \\
\hline Genital anomaly & + & & + & + \\
\hline Joint contractures & + & + & - & + \\
\hline Syndactyly & + & - & - & + \\
\hline Tracheobronchial anomalies & $?$ & $?$ & + & \pm \\
\hline
\end{tabular}

+ Anomaly or feature present, - anomaly or feature absent, ? presence or absence of anomaly not known or described. and Parsons. ${ }^{4}$ These subjects shared a number of significant physical features including sagittal synostosis, growth and developmental retardation, low set ears, contractures, micrognathia, hypertelorism, and others (table). The original report described two sibs with failure to thrive, severe mental retardation, sagittal craniosynostosis, hypertelorism, strabismus, low set and dysplastic ears, retrognathia, mandibular ankylosis, submucous cleft palate, aplasia uvulae, complex cardiovascular malformations, mild contractures of the large joints, syndactyly, hypogenitalism, hypoplastic kidneys, and rib anomalies. ${ }^{3} \mathrm{~A}$ first cousin to these sibs had trigonocephaly but no other morphological abnormalities and had normal development. The trigonocephaly in the first cousin was not thought to be related to the craniosynostosis in the proband and sib in that report. ${ }^{3}$ The second report ${ }^{4}$ described a child who had the following features in common with the patients reported by Pfeiffer $e t a^{3}$ : growth retardation, mental retardation, sagittal synostosis, hypertelorism, low set ears, mandibular ankylosis, micrognathia, a congenital heart defect, frontal atrophy, and ventriculomegaly. The patient described by Stratton and Parsons ${ }^{4}$ also had tracheobronchial anomalies and hypogenitalism. On the basis of the similarities among these patients and the child described in this report, we conclude that the patient described herein has the same disorder as the patients described by Pfeiffer $e t$ $a l^{3}$ and Stratton and Parsons. ${ }^{4}$

The craniofacial and genital anomalies in these four patients suggest that they should be considered as a distinct nosological group although the small number of patients does not allow a definitive conclusion that this is a unique constellation of anomalies. Nevertheless, as a group, these four children share many features. The differential diagnosis has been discussed previously. ${ }^{3}$ The heart defects identified in the previous patients included a ventricular septal defect, an atrial septal defect (in all three patients), a patent ductus arteriosus, Fallot's tetralogy, infundibular, valvular, and peripheral stenoses, and anomalous pulmonary venous return. The variety of heart defects in these patients and the heterogeneity of their origin suggest that the cardiac manifestations in this disorder are variable. In spite of the fact that the eponym for this disorder indicates the presence of cardiac anomalies, it is rare that an anomaly is found to be an invariant feature of any syndrome. The absence of a heart defect in the patient described herein suggests that a congenital heart defect is not an obligatory feature of this condition.

The aetiology of this rare disorder is not known. It is unlikely that a teratogenic agent is responsible since the twin of our patient is unaffected and the sibs originally reported are both affected and had no identified overlapping or significant exposures. ${ }^{3}$ Multifactorial inheritance is possible but is not a common aetiology of multiple congenital anomaly syndromes. ${ }^{5}$ Chromosome analysis was normal in all the patients; however, the possibility of a submicroscopic deletion or uniparental disomy 
cannot be excluded. $\mathrm{X}$ linked inheritance is excluded by the fact that one of the sibs reported by Pfeiffer was female and had a normal karyotype (RA Pfeiffer, personal communication). The possibility of a spontaneous mutation in a gene inherited in an autosomal dominant pattern can not be excluded. That this mutation could have occurred either in the gonads, resulting in gonadal mosaicism in one of the parents, or in the gamete involved in conception is consistent with the present pedigree and with the previous reports. If this is a condition inherited in an autosomal dominant pattern, then reduced penetrance with variable expressivity is also possible, and could account for the recurrence in sibs. A gene inherited in an autosomal recessive pattern is also compatible with these cases and is supported by the report of occurrence in sibs. ${ }^{3}$ In this regard it is noteworthy that the three unions that resulted in these four children are not known to be consanguineous. We agree with the previous authors that a gene inherited in an autosomal dominant or recessive pattern are plausible aetiological hypotheses for this syndrome. Although recessive inheritance is more likely given that one of three families has a sib recurrence, autosomal dominant inheritance must still be considered as a possibility.

We conclude that Pfeiffer type cardiocranial syndrome is a distinct craniosynostosis syndrome of indeterminate aetiology although autosomal recessive or dominant inheritance are most likely. Description of additional patients will lead to an improved understanding of the spectrum of anomalies and inheritance of this disorder.

The authors thank Chris Cunniff, Susan Hassed, and Anthony Wynshaw-Boris for critical review of the manuscript, James I Wynshaw-Boris for critical review of the manuscript, James $L$ Christianson for performing the cardiological evalulation, and
$M$ Michael Cohen for interpretation of skull radiographs and constructive comments.

1 Cohen MM Jr. Craniosynostosis update 1987. Am $\mathcal{f} \mathrm{Med}$ Genet 1988;suppl 4:99-148.

2 Winter R, Donnai D. Conference report. First Robert J Gorlin conference on human dysmorphology, Minneapolis, 14-15 October 1991. Clin Dysmorphol 1992;1:57-61.

3 Pfeiffer RA, Singer H, Zschiesche S. Sagittal craniostenosis, congenital heart disease, mental deficiency and various dysmorphies in two sibs - a "new" syndrome? Eur f Pediatr 1987;146:75-8.

4 Stratton RF, Parson DS. Third case of Pfeiffer-type cardiocranial syndrome. Am $\mathcal{F}$ Med Genet 1989;34:587-8.

5 Jones KL. Genetics, genetic counseling, and prevention via early fetal recognition relative to single gene defects and patterns of malformation. In: Smith's recognizable patterns of human malformation. 4th ed. Philadelphia: Saunders, 1988:641-2. 